\title{
Clinical Observations Supplemental Qualifiers Dataset
}

National Cancer Institute

\section{Source}

National Cancer Institute. Clinical Observations Supplemental Qualifiers Dataset. NCI

Thesaurus. Code C147192.

A dataset containing supplemental information, specifically non-standard variables, to parent records in the clinical observations domain. 